\title{
Strong genetic differentiation of the East-Himalayan Megacodon stylophorus (Gentianaceae) detected by Inter-Simple Sequence Repeats (ISSR)
}

\author{
X.-J. GE ${ }^{1}$, L.-B. ZHANG ${ }^{1}$, Y.-M. YUAN ${ }^{2, *}$, G. HAO ${ }^{1}$ and T.-Y. CHIANG ${ }^{3}$ \\ ${ }^{1}$ South China Botanical Garden, Chinese Academy of Sciences, Guangzhou 510650, P.R. China; ${ }^{2}$ Institut \\ de Botanique, Université de Neuchâtel, Emile-Argand 11, CH-2007 Neuchâtel, Switzerland; \\ ${ }^{3}$ Department of Biology, Cheng-Kung University, Tainan 701, Taiwan; *Author for correspondence \\ (e-mail: yong-ming.yuan@unine.ch; fax:+41-32-7183001)
}

Received 2 June 2003; accepted in revised form 25 November 2003

Key words: East Himalaya, Genetic diversity, Genetic drift, Hengduan Mountains, ISSR, Megacodon stylophorus

\begin{abstract}
Megacodon stylophorus (Clarke) Smith is a perennial alpine herb endemic to the species-rich eastern Himalayan region. Its populations are locally scattered as isolated patches throughout this region. Genetic variation within and among six populations of this species was assessed using ISSR fingerprinting with 13 primers. High levels of genetic diversity exist within species $\left(P=69.83 \%, H_{\mathrm{T}}=0.1949\right.$ and $\left.H_{\mathrm{sp}}=0.3047\right)$, while the within-population diversity is low $\left(P=11.21 \%, H_{\mathrm{E}}=0.0532\right.$ and $H_{\mathrm{pop}}=$ 0.0792). Extraordinarily high levels of genetic differentiation were detected among populations based on various statistics, including Nei's genetic diversity analysis (72.7\%), Shannon's diversity index (74.01\%) and AMOVA (80.70\%). That is, populations shared low levels of genetic identity $(I=0.8203 \pm 0.0430)$. This genetic structure was probably due to severe genetic drift of the small-sized patchy populations resulting from postglacial habitat fragmentations. The observed genetic structure of the populations implies that as many populations as possible should be considered for any in situ and ex situ conservation practice on this species.
\end{abstract}

\section{Introduction}

The Eastern Himalaya is one of the 25 global (one of the two in the northern hemisphere) biodiversity 'hotspots' (Myers 1988; Wilson 1992; Myers et al. 2000). The area comprises Nepal, Bhutan, and neighbouring states of northern India along a continuous sector of the southeast Tibet, southwest Sichuan, and northwest Yunnan provinces of China. This region is the meeting ground of the Indo-Malayan, Indo-Chinese, and eastern Asian biogeographical realms following the formation of the Himalayas, which resulted from the collision of the India plate with the Laurasia landmass (Behera et al. 2002). Studies have shown that this region was a centre of active speciation and a refugium for various flowering plants during glacial maxima (Takhtajan 1969; Rao 1994). A conservative estimate suggests that over 3000 dicot and 1000 monocot species are endemic to the Himalayas (Mani 1978). Being a part of the eastern Himalayan area, Hengduan Mountains lie at the eastern end of this area and extend from west Sichuan and north Yunnan provinces to east Tibet. The Hengduan Mts. comprise a series of spectacular north-south trending ridges along four major rivers of Asia, that is, Brahmaputra, Salween, 
Mekong, and Changjiang (Yangtze) Rivers, and coincide in large part with the eastern Himalayan biodiversity hotspot. The biota of the Hengduan Mts. is renowned for its typical examples of phyletic radiations and concomitant high levels of endemism as well as species and generic richness (Raven and Axelrod 1978; Wilson 1992; Ying et al. 1993). This region was a centre of species diversification during the Tertiary and a refugium for many Laurasian angiosperms, such as Rhododendron, Primula, and Gentiana (Wu 1988). The extraordinarily high diversity appears to be a function of the extreme topographic variation and complexities with deep valleys coupled with recently uplifted mountains. However, despite the richness, the species diversity in this region is facing serious environmental threats due to human over exploitation, including forest destruction and subsequent soil erosion. The high potential instability and inherent vulnerability of mountain ecosystems render the Himalaya region one of the ecologically fragile biogeographic zones (Rodges and Panwar 1988). Loss of habitat by deforestation and excessive grazing pressure in high altitude pastures now threaten the survival of endemic and rare plants in the Hengduan Mts. (Kala 2000; Rai et al. 2000). It is urgent to initiate conservation of the endemic plants in this region.

Genetic diversity, species richness and assemblages are the three main levels for conservation of biodiversity (Secretariat of the Convention on Biological Diversity 2001). Levels of genetic variation within and among natural populations provide fundamental information on the evolutionary processes that bring about divergence within species and lead to speciation ultimately (Krauss 1997) and for the establishment of effective and efficient conservation practices (Hamrick and Godt 1996). Due to the complicated topography of the areas and the low accessibility, biodiversity studies in this region are limited and mostly focus on taxonomic treatment and botanical inventory. No study has been conducted on genetic structure of the endemic species from this region. A genetic study at the population level for an endemic genus will provide insights into both historical processes and ongoing evolutionary mechanisms in maintaining the extraordinarily high biodiversity in this region.

Megacodon is a genus of the Gentianaceae. It is a relatively primitive element within the tribe Gentianeae (Yuan and Küpfer 1995; Chassot et al. 2001), and consists of only two species. While M. venosus is limited to a small area in central China (Chongqing and western Hubei), M. stylophorus is endemic to the eastern Himalayan regions ranging from northwest Yunnan and southwest Sichuan to southwest Tibet in China, extending into Sikkim, Bhutan, Nepal, and northeast India. Plants usually grow in montane habitats beside streams, shrubs or forest margins at an altitude of $3000-4400 \mathrm{~m}$. Although this species is locally abundant, its populations are scattered as isolated patches across mountains throughout this region. With pendant and campanulate corolla, the height of the perennial herb can be more than $100 \mathrm{~cm}$. Its flowers are large and pale yellow-green, ca. $5 \mathrm{~cm}$ in diameter with a short (ca. $1 \mathrm{~cm}$ long) corolla tube. Seeds are oblong, $3-4 \mathrm{~mm}$ long and $2.2-2.5 \mathrm{~mm}$ in diameter, with rugate seedcoat. The plant flowers in June and July, and sets fruit from July to September (Ho and Pringle 1995). Except for its taxonomic and phylogenetic relationships, this species has been so far poorly 
studied. Nothing is known about its breeding system, population genetic structure, or intraspecific differentiation across its distribution.

Among the various molecular methods for detecting genetic diversity, a technique amplifying inter-simple sequence repeats (ISSR) is a powerful tool for investigating genetic variation within species (Gupta et al. 1994; Zietkiewicz et al. 1994; Wolfe and Liston 1998). Recent ISSR studies of natural populations have demonstrated a hypervariable nature of the markers and their potential use for population-level studies (Culley and Wolfe 2001). Technically, the ISSR reaction is more specific than RAPD amplification due to the longer SSR-based primers, thus enabling higher-stringency DNA amplifications (Wolfe et al. 1998). The high-stringency results in very few problems with reproducibility, a common criticism against the lowstringency RAPD assay (Yang et al. 1996). Limitations of the ISSR technique, as with RAPDs, are that bands are scored as dominant markers and that genetic diversity estimates are based on diallelic characters.

As the primary step in investigating the genetic diversity of M. stylophorus, the present study addresses the following questions by using the ISSR molecular markers: (i) What are the levels of ISSR variation in populations of $M$. stylophorus? (ii) What is the degree of among-population differentiation in this species? (iii) How does this information relate to that measured in other species which have the same patterns of geographical distribution? (iv) What are the applications of the population genetic information for an effective and efficient conservation of this species?

\section{Material and methods}

\section{Plant material}

Leaves of 136 individuals of M. stylophorus were collected from six populations in southwest China (Figure 1, Table 1). Individuals 5-10 m apart from one another were sampled randomly. The leaves were dried with silica-gel. The sampled populations represent the major mountains (with altitudes all over $4000 \mathrm{~m}$ a.s.l.) that are isolated by either surrounding relatively low plateaus (altitude around $2000 \mathrm{~m}$ ) or the major valleys in southwest Sichuan and northwest Yunnan provinces of China. These populations grow in the alpine forest or bushes of mixed Abies, Picea, Rhododendron, Sorbus, etc. between 3300 and $4000 \mathrm{~m}$ a.s.l. Their habitat represents the richly endowed yet rather stable primitive environment in the sampled regions.

\section{DNA extraction and PCR amplification}

Genomic DNA was extracted from 0.5 to $1.0 \mathrm{~g}$ of dried leaf tissue using the CTAB method described by Doyle (1991). DNA extractions were quantified by comparing band intensities with known standards of lambda DNA on $1 \%(\mathrm{w} / \mathrm{v})$ agarose gels. In a preliminary study, 100 primers (Biotechnology Laboratory, University of 


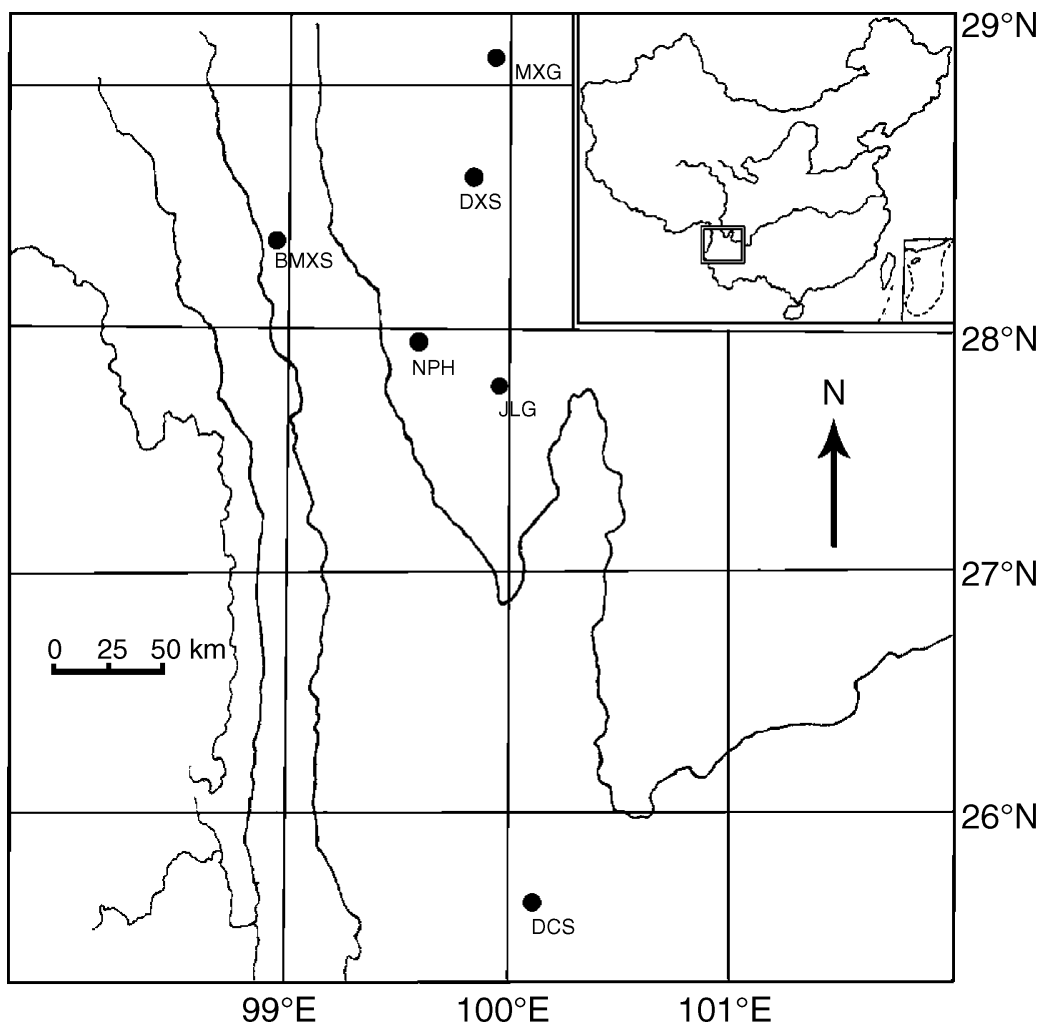

Figure 1. Map showing the locations of the populations of M. stylophorus sampled.

Table 1. Sites of the populations surveyed.

\begin{tabular}{|c|c|c|c|c|c|c|}
\hline Population & Pop. code & Location & $\begin{array}{l}\text { Latitude } \\
(\mathrm{N})\end{array}$ & $\begin{array}{l}\text { Longitude } \\
\text { (E) }\end{array}$ & $\begin{array}{l}\text { Elevation } \\
(\mathrm{m})\end{array}$ & $\begin{array}{l}\text { Sample } \\
\text { size }(N)\end{array}$ \\
\hline \multicolumn{7}{|l|}{ Northwest Yunnan } \\
\hline Bai-Mang-Xue-Shan & BMXS & Deqen & $28^{\circ} 23^{\prime}$ & $98^{\circ} 58^{\prime}$ & 3800 & 22 \\
\hline Dian-Cang-Shan & DCS & Dali & $25^{\circ} 40^{\prime}$ & $100^{\circ} 07^{\prime}$ & 3900 & 23 \\
\hline Ji-Li-Gu & JLG & Zhongdian & $27^{\circ} 44^{\prime}$ & $99^{\circ} 58^{\prime}$ & 3300 & 23 \\
\hline Na-Pa-Hai & $\mathrm{NPH}$ & Zhongdian & $27^{\circ} 53^{\prime}$ & $99^{\circ} 38^{\prime}$ & 3650 & 21 \\
\hline \multicolumn{7}{|l|}{ Southwest Sichuan } \\
\hline Da-Xue-Shan & DXS & Xiangcheng & $28^{\circ} 38^{\prime}$ & $99^{\circ} 50^{\prime}$ & 4000 & 23 \\
\hline Ma-Xiong-Gou & MXG & Xiangcheng & $29^{\circ} 09^{\prime}$ & $99^{\circ} 55^{\prime}$ & 3850 & 24 \\
\hline
\end{tabular}

British Columbia, primer set \# 9, Vancouver, BC, Canada: http://www.biotech. ubc.ca/services/naps/primers/Primers.pdf) were screened for PCR amplification. Thirteen of these ISSR primers (UBC \# 807, 808, 810, 811, 827, 830, 836, 842, 
$846,857,859,864$ and 888) that gave clear, reproducible banding patterns were chosen for final analysis. Polymerase chain reactions (PCR) were carried out in a volume of $20 \mu \mathrm{L}$ consisting of ca. $20 \mathrm{ng}$ of template DNA, $10 \mathrm{mM}$ Tris- $\mathrm{HCl}(\mathrm{pH}$ 9.0), $50 \mathrm{mM} \mathrm{KCl}, 0.1 \%$ Triton $\mathrm{X}-100,2.5 \mathrm{mM} \mathrm{MgCl}_{2}, 0.1 \mathrm{mM}$ dNTPs, $2 \%$ formamide, $0.2 \mu \mathrm{M}$ primer, 1.5 units of Taq polymerase (Shanghai Sangon Biological Engineering Technology and Service Co. Ltd., Shanghai, China) and double distilled water on a MJ Research 96-well thermal cycler with hot bonnet following the conditions of Ge and Sun (1999). The amplification products were separated via electrophoresis on $2.0 \%(\mathrm{w} / \mathrm{v})$ agarose gels (migration distance: $10 \mathrm{~cm}$ ) with $0.5 \times$ TBE buffer and visualized using ethidium bromide staining $(0.1 \mu \mathrm{g} / \mathrm{mL})$. The amplified DNA fragments were documented by using image analysis software LabWorks Software Version 3.0 (UVP, Upland, CA 91786, USA). Negative controls, lacking template DNA, were included in each PCR set to test for the possibility of contamination.

\section{Data analysis}

Only bands that could be unambiguously scored were used in the analysis. ISSR profiles were scored for each individual as present (1) or absent (0) of a specific band. A set of measures of intra- and inter-population genetic statistics were generated using the program POPGENE 1.31 (Yeh et al. 1999), including Nei's (1973) gene diversity, the percentage of polymorphic loci $(P)$, expected heterozygosity $\left(H_{\mathrm{E}}\right)$, total genetic diversity $\left(H_{\mathrm{T}}\right)$, genetic diversity within population $\left(H_{\mathrm{S}}\right)$, genetic diversity between populations $\left(D_{\mathrm{ST}}\right)$ and the relative magnitude of genetic differentiation among populations $\left(G_{\mathrm{ST}}=D_{\mathrm{ST}} / H_{\mathrm{T}}\right)$. Based on the island model, gene flow was inferred indirectly using Wright's $(1931)$ formula: $N_{\mathrm{m}}=0.25\left(1-F_{\mathrm{ST}}\right) / F_{\mathrm{ST}}$. Nei's (1972) genetic identity $(I)$ and genetic distance $(D)$ were calculated for all pairwise combinations of populations.

Shannon's index was also employed to characterize the gene diversity and distribution of the variation. Shannon's index of gene diversity was calculated as $H_{\mathrm{o}}=-\Sigma p_{i} \log _{2} p_{i}$ (Lewontin 1972), in which $p_{i}$ is the frequency of a given ISSR fragment. $H_{\mathrm{o}}$ was calculated at two levels: the average diversity within populations $\left(H_{\text {pop }}\right)$, and the total diversity $\left(H_{\mathrm{sp}}\right)$. The proportion of diversity among populations was estimated as $\left(H_{\mathrm{sp}}-H_{\mathrm{pop}}\right) / H_{\mathrm{sp}}$.

In addition, an analysis of molecular variance (AMOVA) was applied to estimate variance components for ISSR phenotypes, partitioning the variation among populations and among individuals. Input data files for the AMOVA v. 1.55 program (Excoffier et al. 1992) were generated using AMOVA-PREP (Miller 1998). The variance components were tested statistically by nonparametric randomization tests using 1000 permutations.

A UPGMA (unweighted pair-group method using arithmetic average) dendrogram was constructed based on the matrix of Nei's genetic distance using the SAHN - clustering and TREE programs from NTSYS-pc 2.0 (Rohlf 1998). In order to test for a correlation between genetic $(D)$ and geographical distances (in $\mathrm{km}$ ) among 
Table 2. Genetic variation in populations of M. stylophorus shown by ISSR. $P$, percentage of polymorphic loci; $H_{\mathrm{E}}$, expected heterozygosity. $H_{\text {pop: }}$ : Shannon's diversity index.

\begin{tabular}{llll}
\hline Population & $P(\%)$ & $H_{\mathrm{E}}$ & $H_{\text {pop }}$ \\
\hline DCS & 16.38 & 0.0649 & 0.0957 \\
JLG & 14.66 & 0.0517 & 0.0774 \\
NPH & 11.21 & 0.0420 & 0.0628 \\
BMXS & 18.10 & 0.0688 & 0.1011 \\
DXS & 10.34 & 0.0372 & 0.0562 \\
MXG & 14.66 & 0.0548 & 0.0819 \\
Mean & 14.23 & 0.0532 & 0.0792
\end{tabular}

Table 3. AMOVA on 136 individuals of 6 populations of $M$. stylophorus using 116 ISSR markers.

\begin{tabular}{|c|c|c|c|c|c|c|}
\hline Source of variation & d.f. & SSD & MSD & $\begin{array}{l}\text { Variance } \\
\text { component }\end{array}$ & $\begin{array}{l}\% \text { total } \\
\text { variance }\end{array}$ & $p$-value ${ }^{\mathrm{a}}$ \\
\hline Among populations & 5 & 1019.4801 & 203.896 & 8.90 & 80.70 & $<0.001$ \\
\hline Within populations & 130 & 276.7699 & 2.129 & 2.13 & 19.30 & $<0.001$ \\
\hline
\end{tabular}

d.f.: Degrees of freedom; SSD: Sum of squares; MSD: Mean squared deviation. ${ }^{\text {a Significance tests after }}$ 1000 permutation.

populations, a Mantel test was performed using Tools for Population Genetic Analysis (TFPGA; Miller 1997) (computing 1000 permutations).

\section{Result}

\section{Genetic diversity}

In this study, we scored totally 116 unambiguous and reproducible electrophoretic bands (loci), among them $81(69.83 \%)$ were polymorphic. The percentages of polymorphic loci $(P)$ for a single population ranged from $10.34 \%$ (Da-Xue-Shan) to $18.10 \%$ (Bai-Mang-Xue-Shan) with an average of $14.23 \pm 2.97 \%$. The average genetic diversity was estimated to be 0.0532 at population level $\left(H_{\mathrm{E}}\right)$ and 0.1949 at the species level $\left(H_{\mathrm{T}}\right)$. The Shannon's indices $\left(H_{\mathrm{o}}\right)$ were 0.0792 at the population level $\left(H_{\mathrm{pop}}\right)$, and 0.3047 at the species level $\left(H_{\mathrm{sp}}\right)$, respectively (Table 2$)$.

Of the total 116 bands scored, $51 \%$ were found in more than $90 \%$ of the sampled individuals, $4 \%$ of the bands were found in less than $30 \%$ of the individuals, $17 \%$ of the bands in $30-69 \%$ individuals, and $28 \%$ of the bands in $70-89 \%$ individuals. Apparently, the ISSR divergence among populations of M. stylophorus was mainly due to frequency differences among the populations rather than local fixation of ISSR fragments in a specific population. 
Table 4. Nei's (1972) genetic distance and geographical distance among the populations of M. stylophorus (upper right: geographical distance in kilometers; Lower left: Nei's genetic distance).

\begin{tabular}{lllllll}
\hline Pop ID & DCS & JLG & NPH & BMXS & DXS & MXG \\
\hline DCS & - & 228 & 250 & 328 & 330 & 386 \\
JLG & 0.2589 & - & 37 & 121 & 102 & 158 \\
NPH & 0.2846 & 0.1927 & - & 85 & 86 & 144 \\
BMXS & 0.1901 & 0.1929 & 0.2203 & - & 89 & 126 \\
DXS & 0.2665 & 0.1105 & 0.1762 & 0.2116 & - & 57 \\
MXG & 0.2352 & 0.1424 & 0.1496 & 0.2343 & 0.1250 & - \\
\hline
\end{tabular}

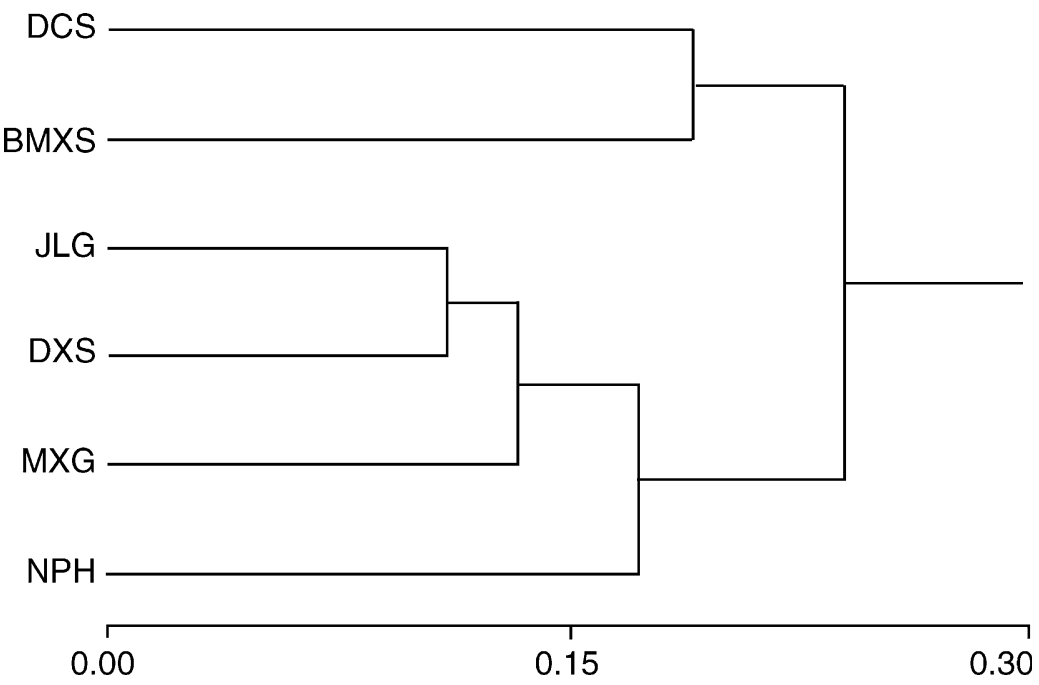

Figure 2. UPGMA dendrogram based on Nei’s (1972) genetic distance.

\section{Genetic structure}

Most of the total gene diversity $\left(H_{\mathrm{T}}\right)$ in $M$. stylophorus was distributed among populations $\left(D_{\mathrm{ST}}\right) . G_{\mathrm{ST}}$ was estimated as 0.727 , indicating that $72.7 \%$ of the genetic variability was distributed among populations, or as $74.01 \%$ based on the Shannon's index. Nei's genetic identities $(I)$ among pairs of populations also suggested a high level of genetic differentiation among populations. The average genetic identity was $0.8203 \pm 0.0430$ (ranging between 0.7523 and 0.8954 ). The overall level of inferred gene flow among populations was extremely low $\left(N_{\mathrm{m}}=0.0939\right)$, suggesting limited pollen and seed dispersal between populations.

Significant genetic differences $(P<0.001)$ among populations were detected based on the AMOVA (Table 3). Of the total molecular variance, $80.70 \%$ was attributable to among-populations diversity and the rest $(19.30 \%)$ to differences 
within populations. The result of a Mantel test with 1000 permutations revealed that the genetic divergence of populations was not significantly correlated with geographic distance (Mantel test, $r=0.5307 ; P=0.1460$ ) (Table 4). That is, an 'isolation by distance' model was not supported. The UPGMA tree (Figure 2) based on Nei's (1972) genetic distance revealed a similar pattern that the genetic distances among the populations do not show a spatial pattern corresponding to their geographic locations (Figure 1). For example, the geographically distant Dian-CangShan and Bai-Mang-Xue-Shan populations show a closer genetic distance to each other (Figure 2).

\section{Discussion}

Genetic variation of ISSR in M. stylophorus and its possible causes

Analyses of the ISSR markers using various statistics (Nei's genetic diversity analysis, Shannon's diversity measure and AMOVA) all revealed similar patterns of genetic structure of populations of M. stylophorus: low genetic variation within populations, and remarkable genetic differentiation among populations. While the ISSR markers were shown to be powerful for investigating genetic variations within species (e.g., Gupta et al. 1994; Zietkiewicz et al. 1994; Wolfe and Liston 1998; Culley and Wolfe 2001), they may give biased estimations on genetic structure of a species due to a possible uneven distribution of the binding sites of the ISSR primers in a genome, such as revealed in Arabidopsis thaliana (Barth et al. 2002). Such a biased inference of ISSR markers in M. stylophorus is yet to be confirmed by using different markers. Nevertheless, similar pattern of genetic variation was found in other rare gentians such as Gentiana pneumonanthe L. in the Gentianaceae family by applying different markers (Raijmann et al. 1994; Oostermeijer et al. 1998).

Megacodon stylophorus is a perennial herb with patchy distribution. The populations are often located in distant mountains, and are strongly isolated from each other by plateaus or valleys. To date there have been no comprehensive studies on its pollination biology and seed dispersal. Our field trips sporadically encountered bumblebees visiting its flowers, indicating the bumblebee as a potential pollinator. Seeds are released when the capsules are dry and dehiscent. Large amounts of seeds are often produced from a single plant, and are numerous from each capsule. Seeds are small sized (3-4 mm long and $2-3 \mathrm{~mm}$ in diameter) and relatively light (ca. $1.5 \mathrm{~g} / 1000 \mathrm{pcs}$ when dried). The seedcoat is slightly rugate. Without any apparent epizoic adaptations, its seeds are probably dispersed over short distances via gravity. Based on its regional distribution and considerations on dispersal of its pollen and seeds, high levels of diversity and differentiation were expected. At the species level, $M$. stylophorus maintains relatively high levels of genetic variation compared to other species with a scattered distribution $\left(H_{\mathrm{E}}: 0.150\right.$, based on allozyme data; Hamrick and Godt 1989) but lower than widespread species $\left(H_{\mathrm{E}}\right.$ : 0.202). However, at the population level, M. stylophorus has a lower level of genetic variation than regionally $\left(H_{\mathrm{E}}: 0.118\right)$ and narrowly distributed species 
$\left(H_{\mathrm{E}}: 0.105\right)$, but is close to endemic species $\left(H_{\mathrm{E}}: 0.063\right)$. A low level of polymorphism was detected in all the six sampled populations of M. stylophorus, ranging from 10.34 to $18.10 \%$ (Table 2).

The genetic structure of plant populations reflects the interactions of various evolutionary processes including the long-term evolutionary history, such as shifts in distribution, habitat fragmentation, and population isolation, mutation, genetic drift, mating system, gene flow, and selection (Schaal et al. 1998). A high level of population differentiation may be explained by several factors, including the species' breeding system, genetic drift or genetic isolation of populations (Hogbin and Peakall 1999).

The scattered distribution of this species throughout the huge eastern Himalayas implies such complicated evolutionary processes. Other molecular phylogenetic studies suggested that Megacodon is a basal genus within the tribe Gentianeae of the family Gentianaceae (Yuan and Küpfer 1995; Chassot et al. 2001; von Hagen and Kadereit 2002). The divergence of Megacodon and its sister groups was dated to the Miocene based on a molecular clock, about 15 million years before present (von Hagen and Kadereit 2002). Considering the large distribution range, M. stylophorus might have been widespread before the Quaternary glaciation, and the present patchy distribution of the populations was probably the results of historical fragmentation due to mountain glaciation and subsequent climatic oscillation. As a matter of fact, welldeveloped mountain glaciers are still active in this region; for example, the Mingyong glacier in Deqen runs down to $2900 \mathrm{~m}$ a.s.l. into forests. Past fragmentation leading to geographical isolation and limited pollen/seed dispersal between relict populations resulted in extraordinarily high diversity among populations and low diversity within populations in this species. Several consequences of the population structure of this relict species after past fragmentation can be examined.

First, M. stylophorus populations in the Hengduan Mts. should have experienced severe extinction and recolonization processes following fragmentation/vicariance events. Frequent extinctions and recolonizations often cause low levels of genetic diversity within species (Qiu and Parks 1994). These are usually linked to changing climatic conditions associated with glacial/interglacial periods during the Pleistocene. Hengduan Mts. consist of a range of south-north running mountains and deep valleys. In response to the cooling-warming cycles of the climate, M. stylophorus populations may have experienced frequent retreat/expansion along the altitude and latitude gradient of the mountains. During the harsh period, M. stylophorus populations retreated downward and southward, and survived in refugia. During favourable periods, they expanded upward and northward. Repeated northward and upward re-colonization of small populations from the valley refugia may account for the loss of alleles in the extant alpine populations. In addition, colonizing populations are more susceptible to founder events and bottlenecks due to fluctuations in the effective breeding population (Nei et al. 1975). Founder events during postglacial re-colonizations and/or bottlenecks may also contributed to the low levels of genetic diversity within populations and high genetic differentiation among patchy populations of M. stylophorus. Similar patterns were found in other plants. Bauert et al. (1998) detected no genetic variation within and among three 
isolated relict populations of Saxifraga cernua, but considerable differences were found among regions.

Second, due to the fragmentation and the subsequent climatic fluctuation in the ice age, the population sizes of $M$. stylophorus may have been remarkably reduced. These small-sized populations were likely subjected to strong genetic drift, especially after a long-time isolation from one another. Genetic drift changes the distribution of genetic variation in two ways: (i) decrease of variation within populations, and (ii) increase of differentiation among populations (Ellstrand and Elam 1993). Populations with continually small effective population sizes are especially susceptible to the loss and reorganization of variation by genetic drift. Genetic drift could particularly result in the loss of low-frequency alleles in populations. In M. stylophorus, we observed only five electrophoretic bands (4\%) with a frequency lower than $30 \%$, suggesting a possible stochastic process of genetic drift. The Mantel test and the UPGMA dendrogram further clarified that the genetic differentiation does not show any spatial pattern and there is no significant correlation between genetic distance and geographic distance, providing further evidence of the action of genetic drift (Dodd and Helenurm 2002).

Third, the identities of long isolated populations have been maintained by limited between-population gene flow. In this study, the patchy habitats of M. stylophorus and the specific topology of the region, mountains separated by deep valleys or intermountain plateaus, have reduced gene flow among populations. Although no explicit study has been done on seed dispersal, the morphology of seeds suggests they are mostly dispersed via gravity, and thus are constrained within short distance. The pollination biology of this species is also unknown. Effective long-distance pollen movement among populations has yet to be confirmed. The observed diversity pattern suggests that gene flow among the populations is limited. The pollen and/or seed-mediated gene flow among populations is probably too low to alleviate genetic drift within populations. Similar situation was also revealed in the rare perennial Gentiana pneumonanthe: the isolation of its populations in nature reserves resulted in relatively high levels of genetic differentiation among populations (Raijmann et al. 1994).

Fourth, genetic structure of a species is dramatically influenced by its breeding system, and selfing can result in low genetic diversity within populations. According to Hamrick et al. (1991), selfing species can have five folds more genetic diversity among populations and only half less diversity within populations than a windpollinated outcrossing species. As mentioned, the breeding system of $M$. stylophorus is not known, and possible selfing due to limitation of the pollinators is yet to be confirmed. Therefore, we cannot rule out the possibility that the observed low within-population diversity was due to a certain degree of selfing.

\section{Implication of the genetic information for conservation}

Habitat-restricted species, occurring in isolated populations, usually tend to be genetically homogeneous at population level, as shown in this study, in Magnolia 
sieboldii ssp. japonica (Kikuchi and Isagi 2002), and the Hawaiian Brighamia insignis (Gemmill et al. 1998). These findings have important implications for conservation of biodiversity. Fragmentation of populations and subsequent genetic drift certainly occur naturally. The natural-history related fragmentation and the induced genetic drift of relict and ancient taxa calls attention for measurement of interpopulational genetic diversity when considering diversity conservation in an area of biodiversity hotspots. Maintenance of a limited number of populations is in such cases not sufficient to preserve the major diversity at the species level. To conserve the genetic diversity of M. stylophorus, it is necessary to preserve as many populations as possible in the wild. Given that most populations are genetically unique, loss of any population will lead to dramatic loss of genetic variation. Concerning ex situ conservation in gardens, introduction should be performed to also include as many populations as possible. Further studies on breeding system and pollination biology of the species are urgently needed to better understand the genetic structure and perform effective conservation of the species.

\section{Acknowledgements}

We are indebted to Dr. Xun Gong for collection of the Dian-Cang-Shan population, and Ms. Yun-Xiao Liu for map illustration. Thanks are also due to Dr. F. Felber for reading the manuscript, and to two anonymous reviewers for their critical reviews and suggestions. This study was financially supported by the Knowledge Innovation Key Project (KSCX2-SW-106) and Field Frontiers Project (Director Foundation of SCBG) of the Chinese Academy of Sciences.

\section{References}

Barth S., Melchinger A.E. and Lübberstedt T.H. 2002. Genetic diversity in Arabidopsis thaliana L. Heynh. investigated by cleaved amplified polymorphic sequence (CAPS) and inter-simple sequence repeat (ISSR) markers. Molecular Ecology 11: 495-505.

Bauert M.R., Kälin M., Baltisberger M. and Edwards P.J. 1998. No genetic variation detected within isolated relict populations of Saxifraga cernua in the Alps using RAPD markers. Molecular Ecology 7: 1519-1527.

Behera M.D., Kushwaha S.P.S. and Roy P.S. 2002. High plant endemism in an Indian hotspot - eastern Himalaya. Biodiversity and Conservation 11: 669-682.

Chassot P., Nemomissa S., Yuan Y.-M. and Küpfer P. 2001. High paraphyly of Swertia L. (Gentianaceae) in the Gentianella-lineages as revealed by nuclear and chloroplast DNA sequence variation. Plant Systematics and Evolution 229: 1-21.

Culley T.M. and Wolfe A.D. 2001. Population genetic structure of the cleistogamous plant species Viola pubescens Aiton (Violaceae), as indicated by allozyme and ISSR molecular markers. Heredity 86: $545-$ 556.

Dodd S.C. and Helenurm K. 2002. Genetic diversity in Delphinium variegatum (Ranunculaceae): a comparison of two insular endemic subspecies and their widespread mainland relative. American Journal of Botany 89: 613-622.

Doyle J. 1991. DNA protocols for plants - CTAB total DNA isolation. In: Hewitt G.M. and Johnston A. (eds) Molecular Techniques in Taxonomy. Springer, Berlin, Germany, pp. 283-293. 
Ellstrand N.C. and Elam D.R. 1993. Population genetic consequences of small population size: implications for plant conservation. Annual Review of Ecology and Systematics 24: 217-242.

Excoffier L., Smouse P.E. and Quattro J.M. 1992. Analysis of molecular variance inferred from metric distances among DNA haplotypes: application to human mitochondria DNA restriction sites. Genetics 131: 479-491.

Ge X.J. and Sun M. 1999. Reproductive biology and genetic diversity of a cryptoviviparous mangrove Aegiceras corniculatum (Myrsinaceae) using allozyme and intersimple sequence repeat (ISSR) analysis. Molecular Ecology 8: 2061-2069.

Gemmill C.E.C., Ranker T.A., Ragone D., Perlman S.P. and Wood K.R. 1998. Conservation genetics of the endangered endemic Hawaiian genus Brighamia (Campanulaceae). American Journal of Botany 85: 528-539.

Gupta M., Chyi Y.-S., Romero-Severson J. and Owen J.L. 1994. Amplification of DNA markers from evolutionarily diverse genomes using single primers of simple-sequence repeats. Theoretical and Applied Genetics 89: 998-1006.

Hamrick J.L. and Godt M.J.W. 1989. Allozyme diversity in plant species. In: Brown A.H.D., Clegg M.T., Kahler A.L. and Weir B.S. (eds) Plant Population Genetics, Breeding and Genetic Resources. Sinauer Associates, Sunderland, Massachusetts, pp. 43-63.

Hamrick J.L. and Godt M.J.W. 1996. Conservation genetics of endemic plant species. In: Avise J.C. and Hamrick J.L. (eds) Conservation Genetics: Case Histories from Nature. Chapman \& Hall, New York, pp. 281-304.

Hamrick J.L., Godt M.J.W., Murawski D.A. and Loveless M.D. 1991. Correlations between species traits and allozyme diversity: implications for conservation biology. In: Falk D.A. and Holsinger K.E. (eds) Genetics and Conservation of Rare Plants. Oxford University Press, Oxford, UK, pp. 75-86.

Ho T.N. and Pringle J.S. 1995. Gentianaceae. In: Wu Z.-Y. and Raven P.H. (eds) Flora of China, Vol. 16. Science Press, Beijing, China, and Missouri Botanical Garden, St. Louis, Missouri, pp. 1-139.

Hogbin P.M. and Peakall R. 1999. Evaluation of the contribution of genetic research to the management of the endangered plant Zieria prostrata. Conservation Biology 13: 514-522.

Kala C.P. 2000. Status and conservation of rare and endangered medicinal plants in the Indian transHimalaya. Biological Conservation 93: 371-379.

Kikuchi S. and Isagi Y. 2002. Microsatellite genetic variation in small and isolated populations of Magnolia sieboldii ssp. japonica. Heredity 88: 313-321.

Krauss S.L. 1997. Low genetic diversity in Persoonia mollis (Proteaceae), a fire-sensitive shrub occurring in a fire-prone habitat. Heredity 78: 41-49.

Lewontin R.C. 1972. The apportionment of human diversity. Evolutionary Biology 6: 381-398.

Mani M.S. 1978. Ecology and phytogeography of high-altitude plants of Northwest Himalaya. Oxford and IBH, New Delhi, India.

Miller M.P. 1997. Tools for Population Genetic Analysis. Version 1.3. Department of Biological Sciences, Northern Arizona University, Flagstaff, Arizona.

Miller M.P. 1998. AMOVA-PREP 1.01: A program for the preparation of AMOVA input files from dominant-markers raw data. Computer software distributed by author.

Myers N. 1988. Threatened biotas: 'hotspots' in tropical forestry. The Environmentalist 8: 1-20.

Myers N., Mittermeier R.A., Mittermeier C.G., da Fonseca G.A.B. and Kent J. 2000. Biodiversity hotspots for conservation priorities. Nature 403: 853-858

Nei M. 1972. Genetic distance between populations. American Naturalist 106: 283-292.

Nei M. 1973. Analysis of gene diversity in subdivided populations. Proceedings of the National Academy of Sciences, USA 70: 3321-3323.

Nei M., Maruyama T. and Chakraborty R. 1975. The bottleneck effect and genetic variability in populations. Evolution 29: 1-10.

Oostermeijer J.G.B., Luijten S.H., Krenova Z.V. and Den Nijs H.C.M. 1998. Relationships between population and habitat characteristics and reproduction of the rare Gentiana pneumonanthe L. Conservation Biology 12: 1042-1053.

Qiu Y.-L. and Parks C.R. 1994. Disparity of allozyme variation levels in three Magnolia (Magnoliaceae) species from the southeastern United States. American Journal of Botany 81: 1300-1308. 
Rai L.K., Prasad P. and Sharma E. 2000. Conservation threats to some important medicinal plants of the Sikkim Himalaya. Biological Conservation 93: 27-33.

Raijmann L.L., Vanleeuwen N.C., Kersten R., Oostermeijer J.G.B., Den Nijs H.C.M. and Menken S.B.J. 1994. Genetic variation and outcrossing rate in relation to population size in Gentiana pneumonanthe L. Conservation Biology 8: 1014-1026.

Rao R.R. 1994. Biodiversity in India: Floristic Aspects. Bisen Singh Mahendra Pal Singh, Dehra Dun, India.

Raven P.H. and Axelrod D.I. 1978. Origin and relationships of the California flora. University of California Publications in Botany 72: 1-134.

Rodges W.A. and Panwar S.H. 1988. Biogeographical Classification of India. New Forest, Dehra Dun, India.

Rohlf F.J. 1998. NTSYS-pc 2.0. Numerical Taxonomy and Multivariate Analysis System. Exeter Software, New York.

Schaal B.A., Hayworth D.A., Olsen K.M., Rauscher J.T. and Smith W.A. 1998. Phylogeographic studies in plants: problems and prospects. Molecular Ecology 7: 465-474.

Secretariat of the Convention on Biological Diversity 2001. Handbook of the Convention on Biological Diversity. Earthscan Publications, London.

Sun H. 2002. Tethys Retreat and Himalayas-Hengduanshan Mountains Uplift and Their Significance on the Origin and Development of the Sino-Himalayan Elements and Alpine Flora. Acta Botanica Yunnanica 24: 273-288.

Takhtajan A. 1969. Flowering Plants, Origin and Dispersal. Oliver and Boyd, Edinburgh, UK.

von Hagen K.B. and Kadereit J.W. 2002. Phylogeny and flower evolution of the Swertiinae (Gentianaceae-Gentianeae): homoplasy and the principle of variable proportions. Systematic Botany 27: 548-572.

Wilson E.O. 1992. The Diversity of Life. Belknap Press of Harvard University Press, Cambridge, Massachusetts.

Wolfe A.D. and Liston A. 1998. Contributions of PCR-based methods to plant systematics and evolutionary biology. In: Soltis D.E., Soltis P.S. and Doyle J.J. (eds) Plant Molecular Systematics II. Kluwer, Boston, Massachusetts, pp. 43-86.

Wolfe A.D., Xiang Q.-Y. and Kephart S.R. 1998. Diploid hybrid speciation in Penstemon (Scrophulariaceae). Proceedings of the National Academy of Sciences, USA 95: 5112-5115.

Wright S. 1931. Evolution in Mendelian populations. Genetics 16: 97-159.

Wright S. 1951. The genetical structure of populations. Annals of Eugenetics 15: 323-354.

Wu Z.Y. 1988. Hengduan mountain flora and her significance. Journal of Japanese Botany 63: 297-311.

Yang W.A., De-Oliveira A.C., Godwin I., Schertz K. and Bennetzen J.L. 1996. Comparison of DNA marker technologies in characterizing plant genome diversity: variability in Chinese sorghums. Crop Science 36: 1669-1676.

Yeh F.C., Yang R. and Boyle T. 1999. POPGENE. Microsoft Windows-based freeware for population genetic analysis. Release 1.31. University of Alberta, Edmonton, Canada.

Ying T.S., Boufford D.E. and Zhang Y.L. 1993. The Endemic Genera of Seed Plants of China. Science Press, Beijing, China.

Yuan Y.-M. and Küpfer P. 1995. Molecular phylogenetics of the subtribe Gentianinae (Gentianaceae) inferred from the sequences of internal transcribed spacers (ITS) of nuclear ribosomal DNA. Plant Systematics and Evolution 196: 207-226.

Zietkiewicz E., Rafalski A. and Labuda D. 1994. Genome fingerprinting by simple sequence repeat (SSR)-anchored polymerase chain reaction amplification. Genomics 20: 176-183. 